\title{
Physical and Chemical Mutation for Enhanced Alpha-Amylase Production by Aspergillus fumigatus NTCC1222 under Solid State Fermentation Conditions Using Agri-Residue Waste
}

\author{
Shalini Singh ${ }^{\star}$, Sanamdeep Singh and Jyoti Mangla
}

\author{
Department of Biotechnology and Biosciences, Lovely Professional University, Punjab, 144411, India
}

\begin{abstract}
The search for better microbial sources of enzymes has long been an area of active research owing to the clear and distinct importance in todays' world where exploration and application of environment friendly products has become a necessity. Though the natural, wild microbial strains, are continuously be searched and explored for their potential for amylase production yet, simultaneous attempts for improved enzyme production are necessary too. In the present study, a comparison between the influence of different mutational treatments (UV treatment and $\mathrm{EMS}-\mathrm{EtBr}$ treatment) on amylase production was studied. Aspergillus fumigatus NTCC1222, an indigenously isolated amylase producer, which has shown an amylase activity of $341.7 \mathrm{U} / \mathrm{mL}$ under optimized conditions of SSF in our previous study, was subjected to UV- and EMS-EtBr- treatment for possible improved amylase production under optimized solid state fermentation conditions. The UV mutated strains yielded an amylase production of $614.2 \mathrm{U} / \mathrm{mL}$ while the chemically (EMS-EtBr) mutated strain produced $814.1 \mathrm{U} / \mathrm{mL}$ of amylase activity thereby indicating the successful enhancement in amylase activity for the test fungal strain.
\end{abstract}

Keywords: Aspergillus fumigatus, Amylase, UV-mutation, EMS-EtBr mutation.

\section{INTRODUCTION}

A day in the history in 1833, Anselme Payen, a French chemist, reported the discovery of first enzyme ever discovered "Diastase" [1]. Since then, extensive studies on enzymes have brought forward their numerous applications, and hence they are widely used in many industrial processes and products [2]. The exponential increase in the application of enzymes in various fields in the last few decades demands extension in both qualitative improvement and quantitative enhancement through strain improvement and medium optimization for higher yield of enzymes [3-5]. Improvement of microbial strains for the overproduction of industrial products has been the earmark of all commercial fermentation processes. Such improved strains can better cater to the parameters of performance, economics and feasibility of the process [3]. Thus, much emphasis is given nowadays on optimization of their use in industries. Amylases are one such extracellular enzyme which constitute $25 \%$ of the world's enzyme market and have found widespread applications in industries such as textile, paper, starch liquefaction, brewing, detergent, etc. [6-11]. Though, the sources of amylases are many such as plants, animals, bacteria and fungi, yet fungal amylases are more popular owing to the distinct advantages

*Address correspondence to this author at the Department of Biotechnology and Biosciences, Lovely Professional University, Punjab, 144411, India; Tel: +919501445358; Fax: +91-1824-506111;

E-mail: shalinisingh.iit@gmail.com associated with them [12-15]. Pertaining to the major share of amylases in world enzyme market, continuous efforts have been made to increase their thermostability, activity and production. Classical random mutagenesis and genetic engineering has been widely used to produce mutant microbial strains with desired characteristics. Irradiation and chemical mutagens are mostly employed mutagens for mutations using random mutagenesis and some of them have considerably increased the characteristics of $\alpha$-amylases in order to satisfy one or all of the 3 E's i.e. Energy, Environment and Economy [9]. Promising results through random mutagenesis thus has encouraged the research in this area $[6,16-19]$. Aspergillus fumigatus has already been shown to be a potential source of industrial enzymes; yet, the huge potential of the same is still to be fully explored $[2,17,20-23]$. The aim of the present study was to enhance the industrial value of already explored as a promising source of amylase, Aspergillus fumigatus NTCC1222, in our laboratory [24-27]. The study further aims to enhance the amylase production for the given fungal strain through mutation.

\section{MATERIALS AND METHODS}

\subsection{Microbial strain and Fermentation Conditions}

The test strain, Aspergillus fumigatus NTCC1222, was cultivated on PDA slants, incubated at $250 \mathrm{C}$ for 24 hours and subsequently stored at $40 \mathrm{C}$. The cultures were maintained as a suspension of spores and hyphal fragments in $15 \%(\mathrm{v} / \mathrm{v})$ sterile glycerol at $-20 \stackrel{\circ}{ } \mathrm{C}$. The

() 2016 Lifescience Global 
fungal strain produced $341.7 \mathrm{U} / \mathrm{mL}$ of alpha-amylase, $0.33 \mathrm{IU} / \mathrm{mL}$ of FPase, $0.46 \mathrm{IU} / \mathrm{mL}$ of CMCase, 0.587 $\mathrm{IU} / \mathrm{mL}$ of pectinase and $106 \mathrm{U} / \mathrm{mL}$ of laccase activity under optimized conditions of solid state fermentation (viz. Incubation period 6 days, incubation $\mathrm{pH}$ 6.0, Incubation temperature $35^{\circ} \mathrm{C}$ [24]).

\subsection{Improvement of Test Fungus Using Physical and Chemical Mutagenesis}

The test fungal strain was grown on wheat bran agar medium (WBA) for 3 days at $37^{\circ} \mathrm{C}$. The fungal culture plates were then exposed to UV radiations (254-260nm) for varying time duration $(3,5,10,15$ and 20 minutes) [6]. The plates were exposed at a distance of $50 \mathrm{~cm}$ away from the center of the Germicidal lamp that served as the source of UV radiations. Due care was taken to perform the aforesaid steps in dark to avoid photo-reactivation. The mycelia discs $(5 \mathrm{~mm}$ diameter each) from exposed plates (mutants), so generated, were used as inoculums production of amylases under optimized solid state fermentation conditions [23]. The amylase activity was subsequently determined [28] which was compared with appropriate (wild-type fungal culture) controls. After 15 days from the first round of exposure to UV, the 1st-round mutants were re-exposed to UV light under the above mentioned conditions. The mutants were repeatedly subcultured to stabilize the same. Amylase activity was subsequently determined and compared with amylase activity for non-UV-exposed fungal culture [28].

$1 \mathrm{ml}$ of $100 \mu \mathrm{l} / \mathrm{mL}$ ethyl methyl sulphonate (EMS) (pH 6.0), was added to $1 \mathrm{~mL}$ of spore suspension (105 spores $/ \mathrm{mL}$ ) $[23,29]$ and incubated at $37^{\circ} \mathrm{C}$ for different time intervals $(30,60$ and 90 minutes) [16]. The EMStreated fungal samples were then plated to obtain survivors and the same were further subjected to SSF conditions to determine amylase activity as previously described. Further, each of the EMS-treated plates, was subsequently treated with $0.5 \mathrm{mg} / \mathrm{ml} \mathrm{EtBr}$ solution (pH 5.0) and incubated at $37^{\circ} \mathrm{C}$ for 30,60 and 90 minutes [30]. After treatment, the spore suspensions were washed thrice by centrifugation $(5000 \mathrm{rpm}$ for 10 min) with buffer ( $\mathrm{pH} \mathrm{6.0)}$ and distilled water. The washed spores were then spread plated on wheat bran agar medium and incubated at $37^{\circ} \mathrm{C}$ for 3 days. The mutated strain was repeatedly subcultured and subsequently, the mutated strains were subjected to enzyme production under optimized conditions of SSF. The enzyme activity was determined as previously described [28].

\section{RESULTS AND DISCUSSION}

Table 1 reports the alpha amylase production by the test fungus after UV-treatment. The enzyme activity of exposed strains did not show promising results when compared to the wild type after $1^{\text {st }}$ round-UV exposure Only a slight increase $(366.3 \mathrm{U} / \mathrm{mL})$ was seen in the amylase activity of the strain exposed to UV for 5 minutes, while for all the other cases of varied treatment times, a decrease in amylase activity was observed in comparison to the control (wild strain). The amylase activity was drastically reduced for a 10minute exposure of UV radiations. A $2^{\text {nd }}$ round of UV exposure was given to the same fungal strain under same conditions as the previous exposure. 2nd round exposure to UV radiation was found to be a great success as the amylase activity of the fungal strain increased significantly. The highest increase was observed in case of 15-min-UV exposure (614.2 U/mL), as compared to wild type strain. Interestingly, UV treatment of 5 minutes to Aspergillus fumigatus was found to be optimum amylase production as per the report by other researchers [6] but in our case though the amylase activity at 5-min-UV-exposure was the best in case of $1^{\text {st }}$ round of UV exposure, yet as the improvement in enzyme activity was not too significant, a $2^{\text {nd }}$ round of UV-exposure was also investigated. And, as observed, after a $2^{\text {nd }}$ round of UV exposure, a 5 minute exposure could not show the highest improvement in amylase activity. This indicated that the said mutation was not stably inherited. Instead, a 15minute exposure during the $2^{\text {nd }}$ round UV-treatment led to a stably-inherited- highest-improvement $(614.2 \mathrm{U} / \mathrm{mL}$ of amylase activity) in amylase activity as compared to the control. A 3-minute-UV-exposure exhibited the poorest performance $(284.2 \mathrm{U} / \mathrm{mL})$, followed by that for 5-minute-UV-exposure $(307.1 \mathrm{U} / \mathrm{mL})$ as compared to control. Varalakshmi et al. (2009) also reported reduction in amylase production on prolonged exposure to UV radiations in case of Aspergillus niger [23]. UV radiations mainly influence the hydrogen bonds of pyrimidic bases. Thus, the most vulnerable regulatory sequences must have been those containing the highest concentration of $C+T[31,32]$, indicating the existence of control of amylase production under such regulon [11]. The UV light is the best studied mutagenic agent in prokaryotic organisms [33].

Table 2 reports the effect of chemical (EMS-EtBr) treatment on amylase production by Aspergillus fumigatus NTCC1222. Ethyl Methane Sulfonate (EMS) is an alkylating agent which carries one, two or more alkyl groups in reactive form. The transfer of methyl or 
Table 1: Effect of UV Treatment on Alpha-Amylase Production by Aspergillus fumigatus

\begin{tabular}{|c|c|c|}
\hline UV exposure & Time of exposure, minutes & Amylase activity, $\mathrm{U} / \mathrm{mL}$ \\
\hline \multirow{5}{*}{$1^{\text {st }}$ exposure } & 3 & $341.3 \pm 2.3$ \\
\hline & 5 & $280.6 \pm 3.1$ \\
\hline & 10 & $366.3 \pm 1.8$ \\
\hline & 15 & $56.2 \pm 1.40$ \\
\hline & 20 & $223.1 \pm 3.4$ \\
\hline \multirow{5}{*}{$2^{\text {nd }}$ exposure (after 15 minutes) } & 3 & $284.2 \pm 2.8$ \\
\hline & 5 & $307.1 \pm 4.5$ \\
\hline & 10 & $466.7 \pm 1.9$ \\
\hline & 15 & $614.2 \pm 1.4$ \\
\hline & 20 & $544.0 \pm 3.2$ \\
\hline
\end{tabular}

Fermentation Conditions: Incubation period (Days): 6 , Temperature $\left({ }^{\circ} \mathrm{C}\right): 37, \mathrm{pH}: 6$, Solid Substrate: Moistening agent: $1: 3$. Enzyme assay conditions: Incubation time (minutes): 60, pH: 5, Temperature $\left({ }^{\circ} \mathrm{C}\right): 55$.

UV treatment conditions: UV wavelength, $\mathrm{nm}: 254-260$, UV Distance, $\mathrm{cm}: 50$

' \pm 'Standard Deviation from the mean.

Table 2: Effect of Chemical Treatment on Alpha-Amylase Production by Aspergillus fumigatus NTCC1222

\begin{tabular}{|c|c|c|c|c|c|c|c|c|c|c|}
\hline \multirow{2}{*}{$\begin{array}{l}\text { Fungal } \\
\text { strain }\end{array}$} & \multicolumn{10}{|c|}{ Amylase activity, $\mathrm{U} / \mathrm{mL}$ at different times of mutagen exposure } \\
\hline & ${ }^{*} 0$ & \multicolumn{3}{|c|}{ *30 } & \multicolumn{3}{|c|}{ *60 } & \multicolumn{3}{|c|}{ *90 } \\
\hline Unexposed & $\begin{array}{r}342.5 \\
\pm 2.4\end{array}$ & \multicolumn{3}{|c|}{-} & \multicolumn{3}{|c|}{-} & \multicolumn{3}{|c|}{-} \\
\hline \multirow[t]{2}{*}{ EMS-treated } & - & \multicolumn{3}{|c|}{$134.2 \pm 1.9$} & \multicolumn{3}{|c|}{$332.2 \pm 1.2$} & \multicolumn{3}{|c|}{$456.7 \pm 2.0$} \\
\hline & ${ }^{*} 0$ & *30 & ${ }^{*} 60$ & ${ }^{*} 90$ & ${ }^{*} 30$ & ${ }^{*} 60$ & ${ }^{*} 90$ & *30 & ${ }^{*} 60$ & ${ }^{*} 90$ \\
\hline Unexposed & - & - & - & - & - & - & - & - & - & - \\
\hline EtBr treated & - & $438.7 \pm 2.1$ & $389.1 \pm 1.7$ & $610.5 \pm 1.4$ & $\begin{array}{c}814.2 \\
\pm 1.6\end{array}$ & $\begin{array}{c}390.7 \\
\pm 1.9\end{array}$ & $491.2 \pm 1.4$ & $394.8 \pm 1.8$ & $\begin{array}{c}353.3 \\
\pm 1.5\end{array}$ & $\begin{array}{c}415.0 \\
\pm 2.2\end{array}$ \\
\hline
\end{tabular}

Fermentation conditions: Incubation period (Days): 6 , Temperature $\left({ }^{\circ} \mathrm{C}\right): 37, \mathrm{pH}: 6$, Substrate: Moistening agent: $1: 3$.

Enzyme assay conditions: Incubation time (minutes): 60, pH: 5, Temperature $\left({ }^{\circ} \mathrm{C}\right): 55$.

Chemical treatment conditions: EMS concentration, $\mu \mathrm{l} / \mathrm{ml}: 100$, EtBr concentration, $\mathrm{mg} / \mathrm{ml}: 0.5$.

ethyl groups to the bases such that their base-pairing potentials are altered and transitions result. Thus, it induces all types of mutations (transitions, transversions, frame shifts and even chromosome aberrations) with various relative frequencies [34-35]. Ethidium bromide intercalates double stranded DNA and deforms the DNA [36]. The insertion of Ethidium bromide in DNA stretches the DNA duplex, leading to frame shift mutations [32]. 90-min-EMS exposed strain showed an increase in amylase activity $(456.7 \mathrm{U} / \mathrm{mL}$ ) while, EMS treatment reduced amylase production for all other exposure times $(134.2 \mathrm{U} / \mathrm{mL}$ at $30 \mathrm{~min}-\mathrm{EMS}$ exposure and $333.2 \mathrm{U} / \mathrm{mL}$ at $60 \mathrm{~min}$-EMS exposure), in comparison to EMS-untreated fungal strain (342.5 $\mathrm{U} / \mathrm{mL}$ ). The enhancement in amylase production by EMS treatment has been reported by other researchers too [37]. EMS-exposed fungal strains were further exposed to $\mathrm{EtBr}$ treatment for 30,60 and 90 minutes and its effect on amylase production under SSF was determined. The amylase activity was found to significantly improve for all the EtBr-treated strains with highest improvement for $60 \mathrm{~min}$ EMS exposed-30 min $\mathrm{EtBr}$ exposed fungal strains $(814.2 \mathrm{U} / \mathrm{mL})$ as compared to wild-type strain. The next best mutagen exposure was found to by 30 min EMS exposed-90 min EtBr exposed fungal strain which exhibited an amylase activity of $610.5 \mathrm{U} / \mathrm{mL}$ in amylase activity as compared to unexposed fungal strain. The rest of the fungal strains can be arranged in terms of decreasing amylase activity, compared to the unexposed fungal strain: 60 min EMS expose-90 min $\mathrm{EtBr}$ exposed $(491.2 \mathrm{U} / \mathrm{mL})>30 \mathrm{~min}$ EMS exposed-30 min EtBr exposed $(438.7 \mathrm{U} / \mathrm{mL})>90 \mathrm{~min}$ EMS exposed-90 min $\mathrm{EtBr}$ exposed $(415.0 \mathrm{U} / \mathrm{mL})>90 \mathrm{~min}$ EMS exposed-30 min $\mathrm{EtBr}$ exposed $(394.8 \mathrm{U} / \mathrm{mL})>60$ min EMS exposed-60 $\mathrm{min} \mathrm{EtBr}$ exposed $(390.7 \mathrm{U} / \mathrm{mL})>30 \mathrm{~min}$ EMS exposed-60 min EtBr exposed $(389.1 \mathrm{U} / \mathrm{mL})>90$ min EMS exposed-60 min EtBr exposed (353.3 U/mL) 
fungal strains. The use of UV and EMS treatment for increasing synthesis of lipases have been reported by Bondkly and Keera (2007) [16]. Malik et al., (2011) has also reported enhancement of enzymes (amyloglucosidase) by EMS-EtBr treatment for Aspergillus niger [38].

\section{CONCLUSION}

The study indicates that the test fungal strain can be improved upon for the production of alpha-amylases under solid state fermentation conditions using UV as well chemical mutagenesis. The UV-mutated strain showed $614.2 \mathrm{U} / \mathrm{mL}$ of amylase production which was much higher than that of control. The chemical treatment drastically improved amylase activity (814.2 $\mathrm{U} / \mathrm{mL}$ ), indicating that chemical treatment was more effective in improving the amylase production by test fungal strain.

\section{REFERENCES}

[1] Payen A. Memoir on the composition of the tissue of plants and of woody [material]. Comptes Rendus 1838; 7: 10521056.

[2] Kirk O, Borchert TV, Fuglsang CC. Industrial enzyme applications. Current Opinion in Biotechnology 2002; 13: 345-351. http://dx.doi.org/10.1016/S0958-1669(02)00328-2

[3] Singh S, Tyagi CH, Dutt D, Upadhyaya JS. Production of high level of cellulase-poor xylanases by wild strains of white rot fungus Coprinellus disseminatus in solid state fermentation. New Biotechnology 2009; 26(3/4): 165-170.

[4] Singh S, Dutt D. Mitigation of adsorbable organic halides in combined effluents of wheat straw soda-AQ pulp bleached with cellulase-poor crude xylanases of Coprinellus disseminatus in elemental chlorine free bleaching. Cellulose chemistry and Technology 2014; 48(1-2): 127-135.

[5] Singh S, Sharma S, Kaur C, Dutt D. Potential of cheap cellulosic residue as carbon source in amylase production by Aspergillus niger $\mathrm{SH}-2$ for application in enzymatic desizing at high temperatures. Cellulose Chemistry and Technology 2014; 48(5-6): 521-527.

[6] Prabakaran M, Thennarasu V, Mangala RA, Bharathidasan R, Chandrakala N, Mohan N. Comparative studies on the enzyme activities of wild and mutant fungal strains isolated from sugarcane field. Indian Journal of Science and Technology 2009; 2(11): 46-49.

[7] Singh S, Dutt D, Tyagi $\mathrm{CH}$. Screening of Xylanases from Indigenously Isolated White Rot Fungal Strains for Possible Application in Pulp Biobleaching. Open Access Scientific Reports 2013; 2(602). http://dx.doi.org/10.4172/scientificreports.602

[8] Singh S, Dutt D, Tyagi $\mathrm{CH}$. Environmentally friendly total chlorine free bleaching of wheat straw pulp using novel cellulase poor xylanases of wild strains of Coprinellus disseminatus. Bioresources 2011; 6(4): 3876-3882.

[9] Singh S, Dutt D, Tyagi CH, Upadhyaya JS. Bio-conventional bleaching of wheat straw soda-AQ pulp with crude xylanases from SH-1 NTCC-1163 and SH-2 NTCC-1164 strains of Coprinellus disseminatus to mitigate AOX generation. New Biotechnology 2010; 28(1): 47-57.

http://dx.doi.org/10.1016/j.nbt.2010.06.005
[10] Tyagi $\mathrm{CH}$, Singh S, Dutt D. Effect of two fungal strains of Coprinellus disseminatus SH-1 NTCC-1163 and SH-2 NTCC1164 on pulp refining and mechanical strength properties of wheat straw soda-AQ pulp. Cellulose Chemistry and Technology 2011; 45(3-4): 257-263.

[11] Kar S, Ray RC, Mohapatra UB. Alpha-amylase production by Streptomyces erumpens MTCC 7317 in solid state fermentation using response surface methodology (RSM). Polish Journal of Microbiology 2008; 57(4): 289-296.

[12] Champreda V, Kanokratana P, Sriprang R, Tanapongpipat S, Eurwilaichitr L. Purification, biochemical characterization, and gene cloning of a new extracellular thermotolerant and glucose tolerant maltooligosaccharide-forming alpha-amylase from an endophytic ascomycete Fusicoccum sp. BCC4124. Bioscience, Biotechnology and Biochemistry 2007; 71(8): 2010-2020. http://dx.doi.org/10.1271/bbb.70198

[13] Sindhu R, Suprabha GN, Shashidhar S. Optimization of process parameters for the production of $\alpha$ - amylase from Penicillium janthinellum (NCIM 4960) under solid state fermentation. African Journal of Microbiology Research 2009; 3(9): 498-503.

[14] Prabhakar A, Krishnaiah K, Janaun J, Bono A. An overview of engineering aspects of solid state fermentation. Malaysian Journal of Microbiology 2005; 1(2): 10-16.

[15] Singh S, Sharma S, Kaur C, Dutt D. UV-and EMS-induced mutations affecting synthesis of alkaloids and lipase in Penicillium roquefortii. Cell Chem and Technol 2014; 48(5-6): 521-527.

[16] EL-Bondkly AM, Keera AA. Arab J Biotech 2007; 10(2): 241 248.

[17] Chadha BS, Rubinder K, Saini HS. Constitutive a-amylase producing mutant and haploid strains of thermophillic fungus Thermomyces lanuginosus. Folia Microbial 2005; 50(2): 133140.

http://dx.doi.org/10.1007/BF02931462

[18] Hanh VV, Pham TA, Kim K. Improvement of fungal cellulase production by mutation and optimization of solid state fermentation. Mycobiology 2011; 39(1): 20-25. http://dx.doi.org/10.4489/MYCO.2011.39.1.020

[19] Bin G, Laisu X, Youfang D, Yanquan L. Screening of alpha amylase high-producing strains from Bacillus subtilis. Journal of Zhejiang 1999; 23: 88-92.

[20] Feitkenhauer H. Anaerobic digestion of desizing wastewater: influence of pretreatment and anionic surfactant on degradation and intermediate accumulation. Enzyme and Microbial Technology 2003; 33: 250-258. http://dx.doi.org/10.1016/S0141-0229(03)00125-X

[21] Gigras P, Sahai V, Gupta R. Statistical Media optimization and Production of ITS a-Amylase from Aspergillus oryzae in a bioreactor. African Journal of Microbiology Research 2002; 45: 203-208.

http://dx.doi.org/10.1007/s00284-001-0107-4

[22] Hmidet N, El-Hadj Ali N, Haddar A, Kanoun S, Alya S, Nasri M. Alkaline proteases and thermostable $\alpha$-amylase coproduced by Bacillus licheniformis $\mathrm{NH} 1$ : Characterization and potential application as detergent additive. Biochemical Engineering Journal 2009; 47: 71-79. http://dx.doi.org/10.1016/j.bej.2009.07.005

[23] Varalakshmi KN, Kumudini BS, Nandini BN, Solomon J, Suhas R, Mahesh B, Kavitha AP. Production and characterzition of $\alpha$ - Amylase from Aspergillus niger JGI24 isolated in Bangalore. Polish Journal of Microbiology 2009; 58(1): 29-36.

[24] Singh S, Singh S, Bali V, Sharma L, Mangla J. Production of fungal amylases using cheap, readily available agriresidues, for potential application in textile industry. BioMed Research International 2014; 9(14).

[25] Singh S, Cheema SK, Kaur B, Mann NK. Influence of ethanol on growth alpha-amylase production for Aspergillus 
fumigatus NTCC1222 under solid state fermentation. International Journal of Engineering Research and Technology 2013; 6(8): 67-69.

[26] Singh S, Cheema SK, Kaur B, Mann NK. Sorbitol: an enhancer of growth and alpha-amylase production for Aspergillus fumigatus NTCC1222 using wheat bran as substrate. International Journal of Biotechnology and Bioengineering Research 2013; 4(6): 555-560.

[27] Singh S, Kaur B, Mann NK, Cheema SK. Influence of calcium chloride on growth and alpha-amylase production for wild and UV-mutated strains of Aspergillus fumigatus. International Journal of Biotechnology and Bioengineering Research 2013; 4(7): 697-702.

[28] Miller GL, Analytical Chemistry, Use of dinitro salicylic acid reagent for determination of reducing sugar 1959; 31: 426429.

[29] Sowmiya E, Jagannathan N, Rajagopal K. Strain Improvement Of Curvularia lunata to enhance the lipid production by chemical mutagenesis. International Journal of Pharma and Bio Sciences 2011; 2(3): 9-27.

[30] Zia MA, Rahman K, Sheikh MA, Khan IA. Chemically treated strain improvement of Aspergillus niger for enhanced production of glucose oxidase. International Journal Of Agriculture \& Biology 2010; 10(407): 964-966.

[31] Nicolás-Santiago SD, Regalado-González C, GarcíaAlmendárez B, Fernández FJ, Téllez-Jurado A, HuertaOchoa S. Physiological, morphological, and mannanase production studies on Aspergillus niger uam-gs1 mutants. Electronic J Biotechnol 2006; 9: 10-19.

http://dx.doi.org/10.2225/vol9-issue1-fulltext-2

[32] Suribabu K, Govardhan TL, Hemalatha KPJ. Strain Improvement of Brevibacillus borostelensis R1 for Optimization of $\alpha$-Amylase Production by Mutagens. J Microb Biochem Technol 2014; 6(3): 123-127. http://dx.doi.org/10.4172/1948-5948.1000132

[33] Meenu M, Santhosh D, Kamia C, Randhir S. Strain improvement of Aspergillus flavus for enhanced production. Ind J Microbiol 2000; 40: 25-32.

[34] Sarikaya E, Gürgün V. Increase of the a-amylase yield by some Bacillus strains. Turk J Biol 2000; 24: 299-308.

[35] Ikram-ul-haq S, Ali A, Saleem JMM. Mutagenesis Of Bacillus licheniformis through Ethyl Methanesulfonate for alpha Amylase Production. Pak J Bot 2009; 41: 1489-1498.

[36] McCann J, Ames BN. Detection of carcinogens as mutagens in the Salmonella/microsome test:assay of 300 chemicals. Proc Natl Acad Sci USA 1975; 72: 5135-5139. http://dx.doi.org/10.1073/pnas.72.12.5135

[37] Sathyaprabha G, Panneerselvam A, Muthukkumarasamy S. Production of cellulase and amylase from wild and mutated fungal isolates. E-Journal of Life Sciences 2011; 1(1): 39-45.

[38] Malik S, Iftikhar T, UI Haq I. Enhanced amyloglucosidase biosynthesis through mutagenesis using Aspergillus niger. Pak J Bot 2011; 43(1): 111-119. 